\title{
REVISTAMARACANAN
}

\section{Crimes, justiças, agentes e instituições: temas de pesquisa em História Social}

Crimes, justice, agents and instituitions: research topics on Social History

Avelino Pedro Nunes Bento da Silva*

Universidade Federal do Amazonas

Manaus, Amazonas, Brasil

Recebido em: 28 abr. 2021.

Aprovado em: 13 out. 2021.

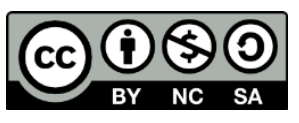

* Professor de História na Secretaria de Estado de Educação e Qualidade de Ensino do Amazonas (SEDUCAM). Mestre e Graduado em Licenciatura Plena em História pela Universidade Federal do Amazonas (UFAM). (avelinopedro21@hotmail.com)

(iD) https://orcid.org/0000-0001-6051-6322

(9) http://lattes.cnpq.br/0717747044496361 


\section{Resumo}

A obra História de crimes, justiça e instituições: fontes judiciais e agentes é uma coletânea organizada por Aguinaldo Rodrigues Gomes, Magda Nazaré Pereira da Costa, Adson Rodrigo Silva Pinheiro e Raick de Jesus Souza, que tem como objetivo apresentar discussões sobre perspectivas de pesquisa em História Social. Reunindo estudos sobre diferentes temáticas e problemáticas do campo do conhecimento histórico, a presente coletânea é resultado da $12^{a}$ edição do Encontro de História da Anpuh-Pará, com o tema Passado e Presente: os desafios da história social e do ensino de história, realizado em formato virtual entre os dias 2 a 4 de dezembro de 2020 .

Palavras-chave: História Social. Fontes judiciais. Agentes. 
A obra História de crimes, justiça e instituições: fontes judiciais e agentes é uma coletânea organizada por Aguinaldo Rodrigues Gomes, Magda Nazaré Pereira da Costa, Adson Rodrigo Silva Pinheiro e Raick de Jesus Souza, que tem como objetivo apresentar discussões sobre perspectivas de pesquisa em História Social. Reunindo estudos sobre diferentes temáticas e problemáticas do campo do conhecimento histórico, a presente coletânea é resultado da $12^{a}$ edição do Encontro de História da Anpuh-Pará, com o tema Passado e Presente: os desafios da história social e do ensino de história, realizado em formato virtual entre os dias 2 a 4 de dezembro de 2020.

A apresentação da coletânea foi escrita pelo historiador Francivaldo Alves Nunes, Presidente da ANPUH-Seção Pará, abordando em seu texto a importância da obra e da realização do evento para o diálogo entre o ensino de história e a história social como campos de pesquisa. Atentando para a relação entre passado e presente na pesquisa histórica, mediante questões socialmente vivenciadas, a proposta da coletânea é reunir trabalhos voltados para uma crítica historiográfica que possibilite ampliar discussões acerca de métodos e análises documentais no campo da História Social.

Na primeira parte, intitulada História, crime e justiça: fontes judiciais e perspectivas de pesquisa, a obra traz estudos que partem do trato metodológico com diferentes fontes, tais como os processos judiciais e a imprensa, vistas estas fontes a partir de perspectivas múltiplas de abordagem histórica sobre os temas de crime e justiça.

O estudo de Felipe de Sousa Miranda, intitulado $A$ sociedade caeteuara a partir dos processos crimes de ferimentos leves da comarca de Bragança-PA (1910-1920): ocupações, conflitos e solidariedades, busca examinar os processos crimes presentes nos Autos Crimes de Ferimentos Leves do arquivo histórico da Comarca de Bragança, no estado do Pará. O capítulo tem o objetivo de construir o perfil social dos sujeitos presentes naqueles processos, propondose também a realizar uma análise qualitativa das narrativas dos processos crimes, possibilitando assim verificar indícios do cotidiano dos réus, ofendidos e testemunhas. A partir da leitura atenta das fontes, Miranda nota dimensões de solidariedade, conflitos e resistências de agricultores, pescadores, jornaleiros, dentre outros que figuram no conjunto documental e que demonstram um cotidiano marcado pelo enfrentamento ao disciplinamento e à ação de autoridades que constituíam discursos de "moralidade" e "civilidade" no Pará das primeiras décadas do século $\mathrm{XX}$.

No capítulo Equilíbrio precário: significados do corpo em Bragança-PA (1916-1940), a historiadora Alessandra Patricia de Oliveira Dias Campos apresenta importante reflexão sobre os significados, valores e representações do corpo feminino na cidade de Bragança, no estado 
do Pará, na primeira metade do século XX. Para sua pesquisa, a autora partiu da análise dos processos judiciais de defloramento, estupro e rapto, documentos esses que foram produzidos pelo Poder Judiciário daquela localidade. O estudo trata ainda de analisar valores morais nos discursos do Estado e como este constituía práticas voltadas para a normatização do comportamento do corpo e da sexualidade. São dimensões discutidas por Campos e que incorporam a problemática da pesquisa sobre como os envolvidos em processos de crimes sexuais construíam definições acerca do corpo das mulheres e, a partir disto, como estas exerciam domínio do próprio corpo conforme seus interesses e necessidades históricas. Partindo da análise das fontes, a autora evidencia importantes considerações sobre práticas cotidianas de mulheres que transgrediam normas de conduta social e enfrentavam a disciplinarização de seus comportamentos e de seus corpos.

O uso da imprensa como fonte é visto na pesquisa do historiador Pedro Guimarães Marques, no capítulo intitulado Guarda de Cais do Porto e segurança paga no Rio de Janeiro novecentista (1919-1945). Por meio da leitura das notícias de roubos na área da Baía de Guanabara, no estado do Rio de Janeiro, o autor observa como determinados grupos - sobretudo de trabalhadores pobres - eram alvo da suspeição policial. Assim, os pobres eram vistos pelos jornais como pessoas "perigosamente situadas a um passo do mundo do ócio e do crime", retratando ainda seus locais de moradia como "foco de proliferação de ladrões". ${ }^{1}$ Diante disso, Marques parte da análise da Guarda de Cais do Porto para refletir sobre os serviços policiais em um período de estruturação das "polícias modernas", contribuindo para discussões sobre a construção da segurança pública no Rio de Janeiro no início do século $X X$, vendo nesse processo a participação de diferentes sujeitos.

Os processos judiciais da comarca de Curitiba, no estado do Paraná, no ano de 1870, são analisados pela historiadora Mayla Louise Greboge Montoia no capítulo intitulado Processos judiciais na história: análise do discurso como ferramenta metodológica para fontes oficiais e contradições discursivas. Verificando uma presença expressiva de imigrantes portugueses naquela documentação do Arquivo Público do Paraná, a autora apresenta uma reflexão sobre relações entre aqueles sujeitos acusados e a cidade, visando perceber relações entre a criminalidade e a imigração. Com a leitura de uma documentação oficial de caráter institucional, produzida por uma linguagem jurídica que uniformiza falas e que possui fins práticos e administrativos, Montoia propõe a problematização de uma suposta ideia que homogeneíza os imigrantes como "bem-sucedidos" ou como "laboriosos". A ferramenta metodológica utilizada pela autora para a análise dos processos judiciais foi a Análise do Discurso, buscando assim investigar nas fontes o sentido das narrativas, bem como o local e o contexto que os sujeitos estão inseridos. Dessa forma, a pesquisa de Montoia amplia perspectivas de análise dos processos judiciais em relação à sua estrutura e aos envolvidos.

A segunda parte do livro, intitulado Instituições, agentes, saberes e práticas científicas: entre o local e o global (século XVIII ao XX), conta com a apresentação de Adson Rodrigo Silva

\footnotetext{
${ }^{1}$ GOMES, Aguinaldo Rodrigues et al (Orgs.). História de crimes, justiça e instituições: fontes judiciais e agentes. Belém: Cabana, 2021, p. 39.
} 
Pinheiro e Raick de Jesus Souza. Nesta parte, a obra reúne pesquisas na área de História das Ciências, com estudos que tratam de ações e práticas institucionais, de histórias de viajantesexploradores, além de discutir a circulação de saberes e práticas científicas. Partindo disso, Pinheiro e Souza destacam a relevância da História das Ciências como campo de investigação que aborda relações sociais entre instituições, agentes, saberes e práticas científicas.

Aimé Bonpland um viajante nas fronteiras é o título do capítulo de Alessandra da Silva que tem o objetivo de tratar da trajetória de vida de Aimé Jacques Alexandre Goujand Bonpland (1773-1858), médico e botânico francês que viveu parte de sua vida na América do Sul, entre o Brasil, o Paraguai e a Argentina. Em torno disso, a autora discute contribuições de Bonpland para a ciência moderna na América do Sul, destacando a parceria com Alexander Von Humboldt (1769-1859) - naturalista e explorador alemão importante por suas contribuições para o desenvolvimento da ciência -, o envolvimento de Bonpland com autoridades políticas na América, bem como seus interesses na pesquisa e no cultivo da erva-mate. Nessa medida, o capítulo apresenta uma proposta de estudo da figura de Bonpland visando apreender a relevância daquele pesquisador para as Ciências Naturais.

Com o título Nas tramas das redes: Observatório Astronômico Antares e suas conexões no Brasil e no Mundo, o capítulo de Wíllivan do Carmo Santos remonta a história do Observatório Astronômico Antares, lembrando ainda da criação do Museu Antares de Ciência e Tecnologia, em 2009, o qual trabalha atualmente na conservação, restauração e valorização patrimonial. Fundado em 1971, na cidade de Feira de Santana, no interior do estado da Bahia, o Observatório é atualmente patrimônio administrativo da Universidade Estadual de Feira de Santana (UEFS), sendo visto pelo autor a partir de sua relevância social enquanto instituição voltada para as populações locais e, igualmente, para a apresentação pública da ciência. Nesses termos, Santos evidencia a dimensão coletiva da ciência, de modo que discute como a produção do conhecimento "depende da interação social entre pesquisadores e instituições, agindo em redes". ${ }^{2}$

O historiador Magno Francisco de Jesus Santos é o autor do capítulo "O estudo da vida íntima do paiz": Felisbelo Freire e a história territorial do Brasil (1906), pesquisa que discute os pressupostos presentes na obra Historia Territorial do Brazil (1906), escrita pelo médico Felisbelo Firmo de Oliveira Freire (1858-1916). Essa obra trata do processo territorial de povoamento do Brasil. Partindo do estudo das vilas, das cidades e das capitanias, Felisbelo Freire se propôs a refletir sobre a questão dos limites entre as unidades federativas. É a partir desta questão que Magno Santos investiga naquela obra uma "escrita da história dos espaços", além de discutir a presença do autor na historiografia. São análises que explicitam contribuições e a relevância da obra de Felisbelo Freire para o estudo de dimensões das experiências sociais e históricas de territórios, espaços e limites de estados do Brasil.

O Proyecto Orgánico para la Urbanización del Municipio, elaborado pela Comisión de Estética Edilicia (CEE) - comissão técnica formada por três arquitetos e um engenheiro, criada

\footnotetext{
2 GOMES, Aguinaldo Rodrigues et al (Orgs.). Op.cit., p. 88.
} 
em 1923 para tratar das transformações urbanas em Buenos Aires, na Argentina -, foi alvo da pesquisa de Ana Carolina Oliveira Alves no capítulo intitulado Propostas de intervenção em construção: agentes, instituições e cidade no Proyecto Orgánico para la Urbanización del Municipio (Buenos Aires, 1925). Por meio da análise do Projeto da CEE, documento que apresenta estudo técnico da comissão acerca de "perspectivas teóricas sobre o crescimento urbano, diagnósticos sobre a cidade e propostas de intervenção", ${ }^{3}$ a autora busca refletir a respeito de interações entre profissionais e instituições. Pensando ainda a construção do campo do urbanismo, evidencia Alves novas abordagens sobre as temáticas urbanas, apreendendo relações entre diferentes escalas, contextos e temporalidades. Nessa medida, a pesquisa apresenta considerações teóricas que ampliam perspectivas de análise no campo da história sobre sentidos múltiplos e relações entre agentes e instituições.

No capítulo Redes científicas, instituições e savants em torno da missão francesa RohanChabot em Angola e Rodésia, Priscila Freitas de Carvalho aborda a missão científica empreendida pelo conde francês Jacques de Rohan-Chabot na colônia portuguesa de Angola, nos anos 1912 a 1914. Tendo como objetivo identificar as redes científicas mobilizadas para a missão, a autora destaca como ponto central a constituição de redes, dentre estas, a rede de cientistas que permitiu a divulgação de resultados do projeto em jornais franceses, legitimando assim o caráter científico daquele empreendimento.

O conjunto de estudos e pesquisas apresentados pela coletânea oferece ao leitor perspectivas amplas de abordagem da pesquisa em história, partindo de considerações teóricas e metodológicas sobre fontes e documentos diversos que possibilitam discutir e refletir sobre temáticas de crimes, justiças, agentes e instituições. Dessa maneira, a relevância da obra para o campo da História Social é vista ao ponto que evidencia outras perspectivas sobre crime e justiça, perspectivas essas que são analisadas através do trabalho com experiências, práticas e valores de múltiplos sujeitos. Outro ponto central de contribuição do livro se refere ao foco às relações entre agentes e instituições a partir de fontes diversas, apreendendo e refletindo sobre seus processos históricos de constituição e reconstituição a níveis local e global. Assim, o livro dialoga com temas de pesquisa em História Social, ao passo que proporciona o contato com uma historiografia que se encontra em produção em diferentes regiões do Brasil.

${ }^{3}$ GOMES, Aguinaldo Rodrigues et al (Orgs.). Op.cit., p. 121. 


\section{Referências}

GOMES, Aguinaldo Rodrigues; COSTA, Magda Nazaré Pereira; PINHEIRO, Adson Rodrigo Silva; SOUZA, Raick de Jesus (Orgs.). História de crimes, justiça e instituições: fontes judiciais e agentes. Belém, PA: Cabana, 2021. 126 p. 